\title{
Digestive System Mixed Neuroendocrine-Non-Neuroendocrine Neoplasms
}

\author{
Louis de Mestier ${ }^{\mathrm{a}, \mathrm{b}}$ Jérôme $\operatorname{Cros}^{c}$ Cindy Neuzillet $^{\mathrm{d}}$ Olivia Hentic $^{\mathrm{b}}$ Axel Egal ${ }^{\mathrm{d}}$ \\ Nelly Muller ${ }^{b}$ Olivier Bouché ${ }^{a}$ Guillaume Cadiot ${ }^{a}$ Philippe Ruszniewski ${ }^{b}$ \\ Anne Couvelard ${ }^{\mathrm{e}}$ Pascal Hammel ${ }^{\mathrm{d}}$ \\ a Department of Hepato-Gastroenterology and Digestive Oncology, Robert-Debré University Hospital, Reims, \\ Departments of ${ }^{\mathrm{b}}$ Gastroenterology and Pancreatology, ${ }^{\mathrm{C} P a t h o l o g y}$, and ${ }^{\mathrm{d}}$ Digestive Oncology, ENETS Centre of \\ Excellence, Beaujon Hospital and Paris-Diderot University, APHP, Clichy, and ' Department of Pathology, ENETS \\ Centre of Excellence, Bichat Hospital and Paris-Diderot University, APHP, Paris, France
}

\section{Keywords}

Adenocarcinoma $\cdot$ Epidemiology $\cdot$ Neuroendocrine tumours · Chemotherapy $\cdot$ Treatment $\cdot$ Prognosis · Mixed tumours their adenocarcinoma counterparts, but also display additional alterations. This advocates for a common origin, and that the presence of a PDNEC component in an adenocarcinoma could indicate a turning point in carcinogenesis.

(c) 2017 S. Karger AG, Basel

\section{Introduction}

Neuroendocrine neoplasms (NEN) are a heterogeneous group of rare neoplasms that represent $1 \%$ of all digestive malignancies [1]. The 2017 World Health Organization classification of NENs relies on the histological grade, based on the proliferation index (Table 1) [2] Mixed neuroendocrine-non-neuroendocrine neoplasms (MiNEN), which were previously termed "MANEC" for "mixed adeno-neuroendocrine carcinoma," are defined by the association of at least two morphologically different neoplastic components, including one neuroendocrine [2-6]. Although heterogeneous, MiNEN are usually highly aggressive neoplasms with poor prognosis and thus should be managed as non-neuroendocrine cancers rather than classical NEN.

\section{KARGER}

(C) 2017 S. Karger AG, Basel 
Fig. 1. Place of MiNEN in the spectrum of neuroendocrine and non-neuroendocrine neoplasms (adapted from Volante et al. [3]). Between the two extremes of pure neuroendocrine and non-neuroendocrine neoplasms, MiNEN can display various percentages of each component (ranging theoretically from 1 to $99 \%$ of the whole neoplasm) as well as various morphological organizations from isolated neuroendocrine cells within a non-neuroendocrine neoplasm to a well-organized neuroendocrine component. Currently, both components composing a MiNEN must represent at least $30 \%$ of the whole tumour.

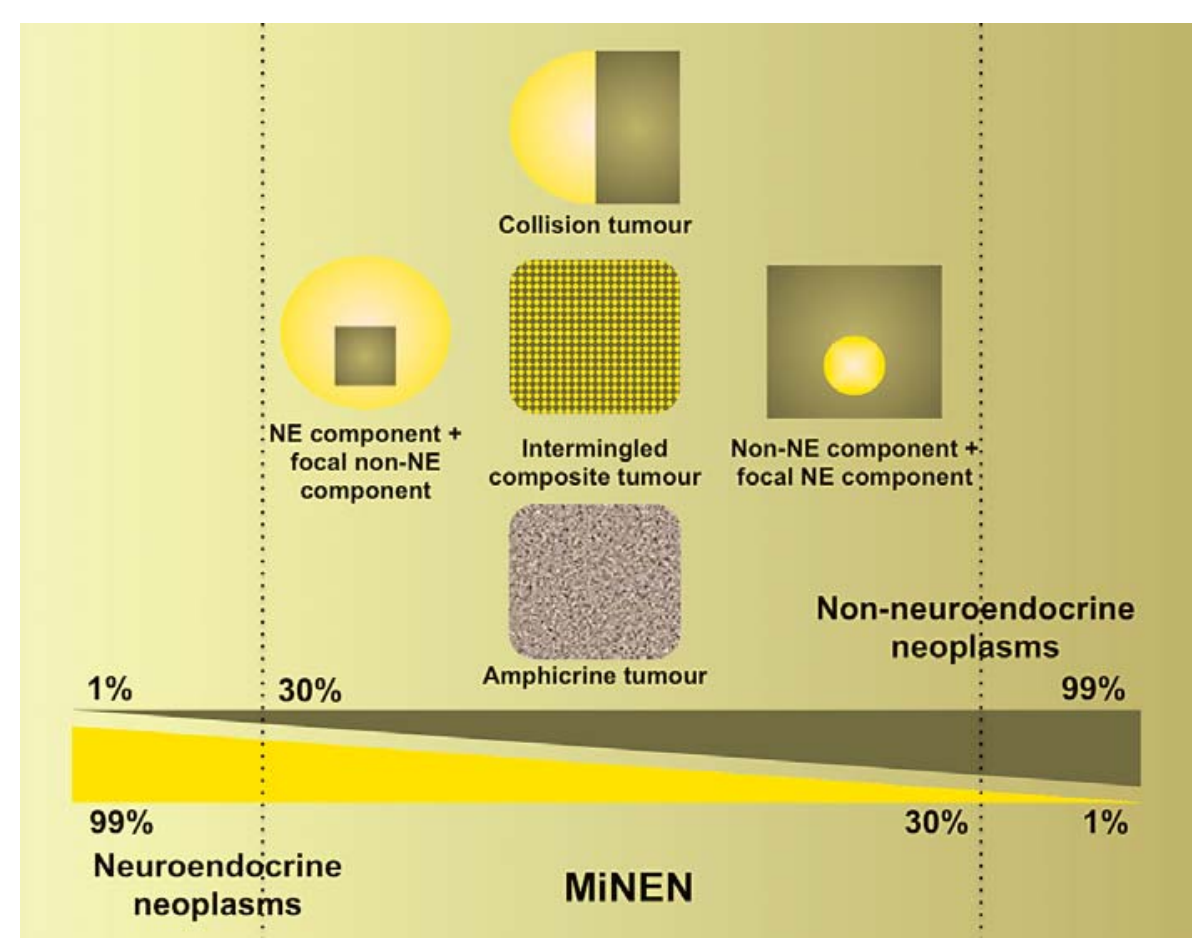

Due to their rarity and heterogeneity, the histogenesis, classification, and therapeutic management of MiNEN are complex and ill-defined. The aim of this review is to discuss the relevance of their pathological classifications and to provide an overview of location-specific clinical and prognostic features while focusing on recent insight into histogenesis and therapeutic issues. To provide a comprehensive and up-to-date review on the current state of knowledge on MiNEN, we searched PubMed, Web of Science and Google Scholar electronic databases for relevant articles published between 1990 and 2016, with no language restrictions, using the following keywords: "mixed neuroendocrine-non-neuroendocrine neoplasm," "mixed adeno-neuroendocrine carcinoma," "mixed endocrine-exocrine carcinoma," "collision tumour," and "amphicrine tumour." A total of 141/234 articles fit our criteria for review and analysis, excluding a number of case reports or limited case series.

\section{MiNEN: Definition and Classification}

MiNEN are neoplasms with two distinct neuroendocrine and non-neuroendocrine cell populations [2]. They can be morphologically classified into three entities: collision, composite, and amphicrine MiNEN (Fig. 1, 2) [4-

Mixed Neuroendocrine-Non-

Neuroendocrine Neoplasms
Table 1. The 2017 World Health Organization classification of neuroendocrine neoplasms [2]

\begin{tabular}{|c|c|c|}
\hline & Ki67, \% & $\begin{array}{l}\text { Mitotic index, mitoses per } \\
10 \text { high-power fields }\end{array}$ \\
\hline Grade 1 & $<3$ & $<2$ \\
\hline Grade 2 & $3-20$ & $2-20$ \\
\hline \multirow[t]{2}{*}{ Grade 3} & $>20$ & $>20$ \\
\hline & Grade & Differentiation \\
\hline $\begin{array}{l}\text { G1 neuroendocrine } \\
\text { tumour }\end{array}$ & Grade 1 & Well differentiated \\
\hline $\begin{array}{l}\text { G2 neuroendocrine } \\
\text { tumour }\end{array}$ & Grade 2 & Well differentiated \\
\hline $\begin{array}{l}\text { G3 neuroendocrine } \\
\text { tumour }\end{array}$ & Grade 3 & Well differentiated \\
\hline $\begin{array}{l}\text { G3 neuroendocrine } \\
\text { carcinoma }\end{array}$ & Grade 3 & Poorly differentiated \\
\hline MiNEN & All grades & $\begin{array}{l}\text { Association of a } \\
\text { neuroendocrine and a non- } \\
\text { neuroendocrine component }\end{array}$ \\
\hline
\end{tabular}



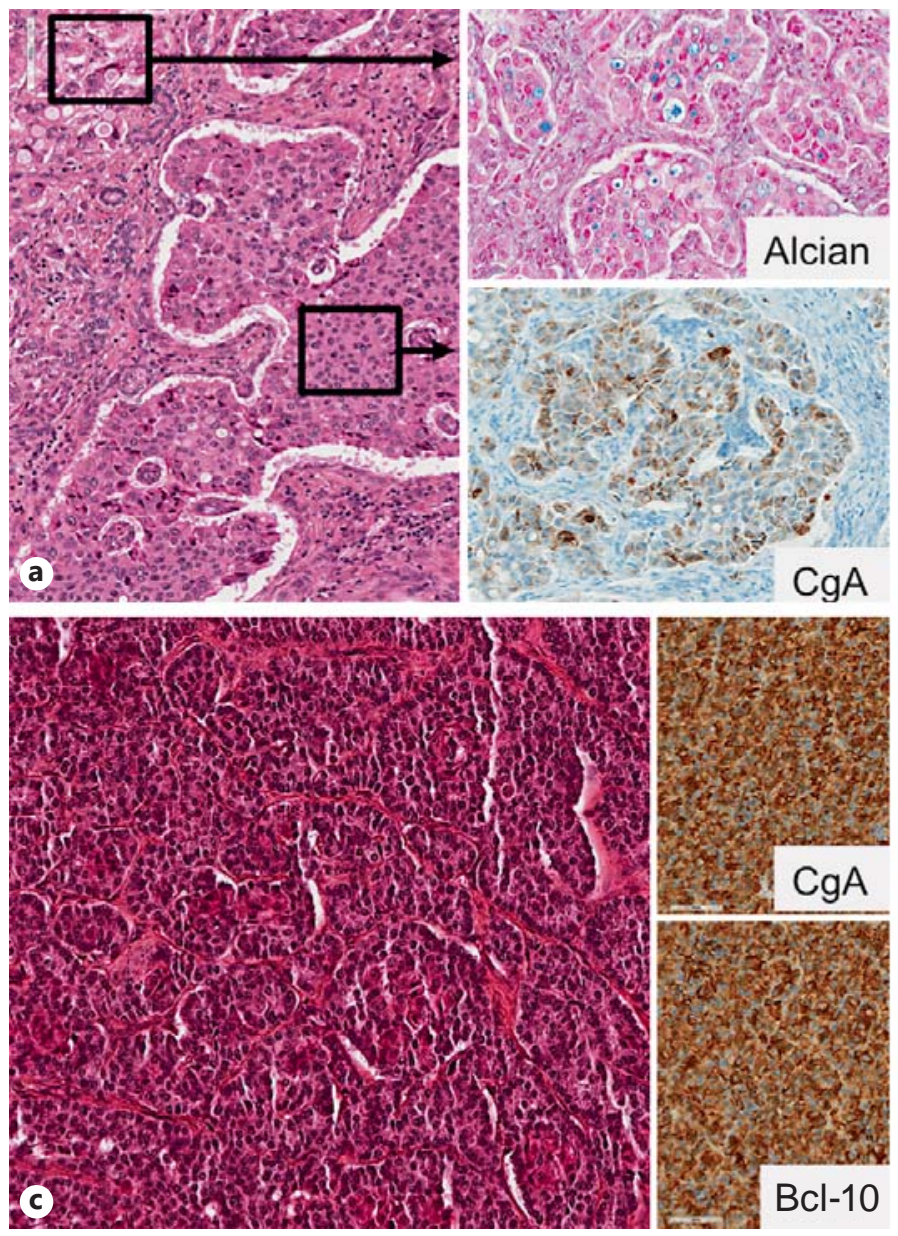

Fig. 2. Multiple histological patterns of MiNEN. a Colon composite MiNEN (left, haematoxylin-eosin-saffron staining, $\times 100$ ) composed of a mucin-producing adenocarcinoma component (upper right, Alcian blue staining, $\times 200$ ) intermingled with a poorly differentiated neuroendocrine carcinoma component (lower right, chromogranin A immunolabeling, $\times 200$ ). b Pancreatic collision MiNEN (left, haematoxylin-eosin-saffron staining, $\times 50$ ) composed of a well-differentiated adenocarcinoma (upper right, haematoxylin-eosin-saffron staining, $\times 100$ ), separated by a fibrous band from a poorly differentiated small-cell carcinoma (lower right, haematoxylin-eosin-saffron staining, $\times 100)$. c Pancreatic

7]. Collision MiNEN may be morphologically suspected by the juxtaposition without mixing of two coexisting, malignant cell populations that do not usually have a common precursor and that remain topographically separate without transition between the two. Composite MiNEN involve two morphologically distinct components that coexist in an intermingled population, or with one predominant component and a focal area of another minority component. Diagnosis of MiNEN is usually facilitated by the presence of at least one well-differentiated
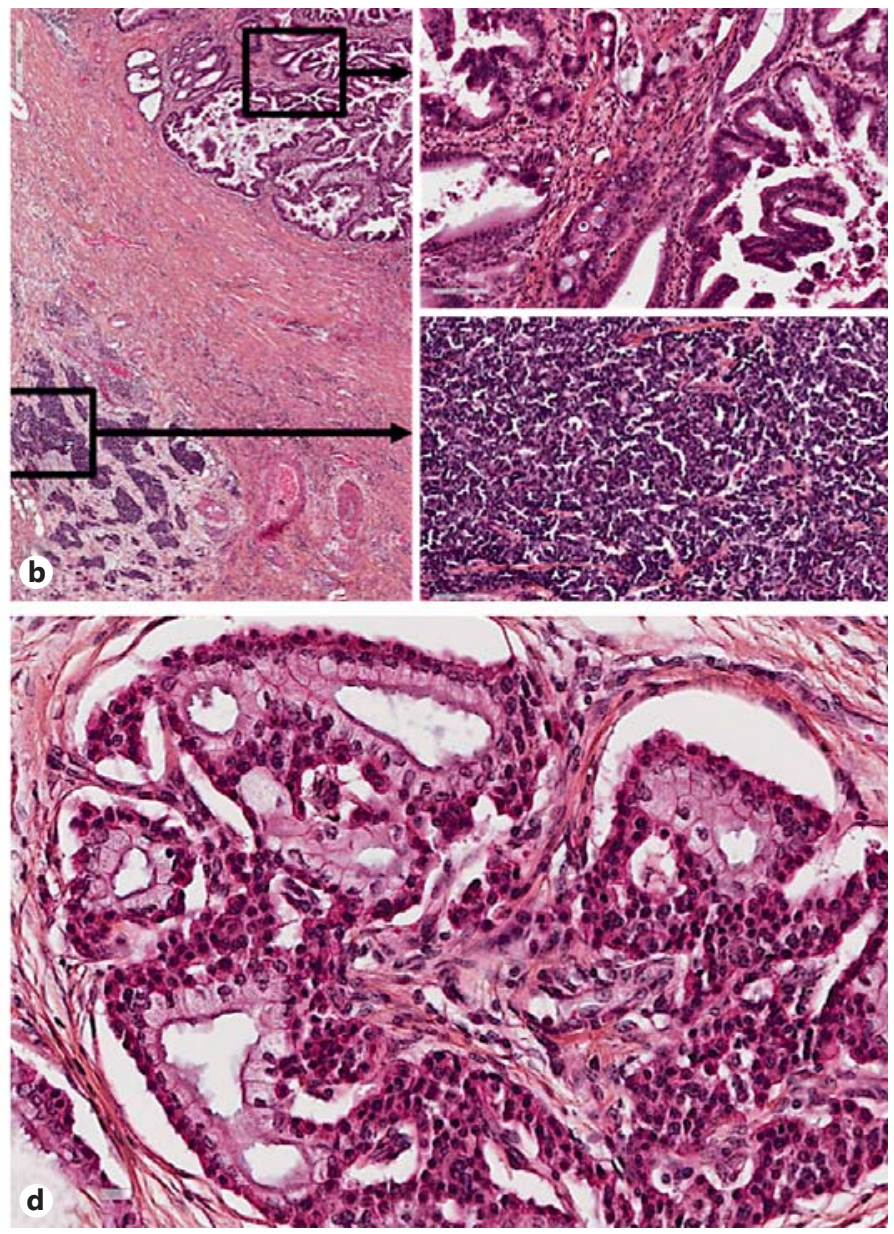

amphicrine MiNEN (left, haematoxylin-eosin-saffron staining, $\times 100$ ) with cells expressing both neuroendocrine (upper right, chromogranin A immunolabeling, $\times 100$ ) and acinar (lower right, Bcl-10 immunolabeling, $\times 100)$ differentiation markers. d Pancreatic ductal adenocarcinoma entrapping and invading a neuroendocrine islet (haematoxylin-eosin-saffron staining, $\times 200$ ). The neuroendocrine cells have features of transdifferentiation toward an exocrine phenotype (cytoplasmic mucin in clarified cells). This confirms "ductuloinsular" pancreatic cell plasticity but should not been mistakenly diagnosed as MiNEN.

component (Fig. 2a, b). However, the two components may be difficult to identify with conventional morphological techniques, particularly when they are poorly differentiated, and their identification may require additional immunohistochemical techniques. In addition to morphological features, the diagnosis of adenocarcinoma is helped by the histochemical Alcian blue staining and the immunohistochemical expression of cytokeratins, or Bcl-10 for acinar-cell carcinoma [2].
Neuroendocrinology 2017;105:412-425 DOI: $10.1159 / 000475527$ de Mestier et al. 
Amphicrine MiNEN is composed of a single cell population that displays the phenotypes of at least two neoplasms. These neoplasms are exceptional and have been described in the stomach, pancreas, appendix, and colon $[8,9]$. They mostly associate neuroendocrine and adenocarcinoma phenotypes, with their cytoplasm containing both neuroendocrine secretory granules and mucin droplets. Amphicrine carcinomas with acinar-cell and neuroendocrine (mostly poorly differentiated neuroendocrine carcinomas - PDNEC) features may also develop in the pancreas (Fig. 2c) [10].

Each component of a MiNEN must theoretically account for at least $30 \%$ of the whole neoplasm (Fig. 1) [11]. This threshold was arbitrarily proposed in $1987[3,5]$. It was hypothesized that the prognosis was influenced by the predominant histological component rather that one accounting for $<30 \%$ of the entire neoplasm. Besides, it aims at preventing clinicians from managing too often these rare neoplasms without treatment guidelines. Nevertheless, a minor (i.e., <30\%) PDNEC component can impair prognosis [12-14]. In addition, this cut-off value only applies to resected samples after examination of the entire neoplasm specimen and particular caution should be taken when evaluating biopsy specimens due to a potential sampling bias (Table 2). The definition of MiNEN also excludes non-neuroendocrine neoplasms with a scattered expression of neuroendocrine markers with no identifiable neuroendocrine cell morphology. This is frequent (40-80\% depending on the location) when systematically studying neuroendocrine marker immunostaining in resected adenocarcinoma specimens $[6,7,12]$. It has no or uncertain prognostic influence, although a positive impact has been suggested in oesophageal adenocarcinoma [13], whereas a negative one was evocated in gastric adenocarcinoma $[15,16]$, cholangiocarcinoma [17], and colorectal adenocarcinoma [18, 19]. Nevertheless, it does not yield therapeutic changes. Hence, systematic search for neuroendocrine marker expression in adenocarcinomas may lead to a risk of over-diagnosed pseudoMiNEN and should not be performed unless a distinct cell component with neuroendocrine morphology is suspected.

In the previous World Health Organization NEN classifications, MiNEN was referred as MANEC for "mixed adeno-neuroendocrine carcinoma," which was not representative of all MiNEN and did not take into account their heterogeneity, since (1) all non-neuroendocrine components are not only adenocarcinoma, but can also be squamous-cell carcinoma, and (2) all MiNEN are not carcinoma, especially those that combine two low-grade
Table 2. Proposal for exploration of neuroendocrine differentiation in case of MiNEN suspicion

\section{Circumstances}

- Observation of a well-differentiated neuroendocrine morphology with an organoid/nodular/solid/trabecular growth pattern

- Observation of a poorly differentiated component (small- or large-cell type)

Methods

- Paraffin-embedded blocks of each cm of tumour to take into account intra-lesion heterogeneity in the quantification of each component

- Identification of neuroendocrine cell morphology

- Identification of neuroendocrine markers 1st choice: chromogranin A and synaptophysin 2nd choice: CD56 (especially for poorly differentiated carcinoma)

- Identification of the main prognostic factors: grading (differentiation, Ki67) and lymphovascular invasion (and which component)

Current conclusions

- MiNEN (each component accounts for $\geq 30 \%$ of the neoplasm)

- Non-neuroendocrine neoplasm with focal neuroendocrine component (the neuroendocrine component accounts for $<30 \%$ of the neoplasm)

- Non-neuroendocrine neoplasm with focal neuroendocrine marker expression (no neuroendocrine component is identifiable morphologically)

Table 3. Classification of MiNEN according to their grade of malignancy

\begin{tabular}{lll}
\hline & $\begin{array}{l}\text { Non-neuroendocrine } \\
\text { component }\end{array}$ & $\begin{array}{l}\text { Neuroendocrine } \\
\text { component }\end{array}$ \\
\hline $\begin{array}{l}\text { High-grade } \\
\text { MiNEN }\end{array}$ & $\begin{array}{l}\text { Carcinoma } \\
\text { adenoma }\end{array}$ & $\begin{array}{l}\text { Poorly } \\
\text { differentiated } \\
\text { neuroendocrine } \\
\text { carcinoma (G3) of } \\
\text { small- or large-cell } \\
\text { type }\end{array}$ \\
& & $\begin{array}{l}\text { Well-differentiated } \\
\text { neuroendocrine } \\
\text { tumour (G1-G2) }\end{array}$ \\
\hline $\begin{array}{lll}\text { Intermediate-grade } \\
\text { MiNEN }\end{array}$ & Carcinoma $^{\text {a }}$ & \\
\cline { 2 - 3 } & $\begin{array}{l}\text { Amphicrine } \\
\text { carcinomas }\end{array}$ & $\begin{array}{l}\text { Well-differentiated } \\
\text { neuroendocrine } \\
\text { tumour (G1-G2) }\end{array}$ \\
\hline Adenoma & &
\end{tabular}

Adapted from La Rosa et al. [6]. ${ }^{\text {a }}$ Carcinoma generally consists of adenocarcinoma but can be squamous-cell or acinar-cell carcinoma as well.
Mixed Neuroendocrine-Non-

Neuroendocrine Neoplasms
Neuroendocrinology 2017;105:412-425 DOI: $10.1159 / 000475527$
415 
components, explaining that the abbreviation "MANET" for "mixed adeno-neuroendocrine tumour" had been proposed [6].

La Rosa et al. $[6,12]$ proposed a classification of MiNEN based on malignancy grade that takes into account the heterogeneity of these malignancies (Table 3). Highgrade MiNEN generally combine a non-neuroendocrine carcinoma (usually adenocarcinoma, but possibly squamous-cell carcinoma or acinar-cell carcinoma in the pancreas as mentioned above) or an adenoma (villous or tubulo-villous) with a PDNEC component, which is generally more aggressive [20-24]. The prognosis of intermediate-grade MiNEN is generally determined by the non-neuroendocrine component rather than the G1 or G2 NET component. However, both components can metastasize in a poorly predictable fashion. Finally, lowgrade MiNEN associate a G1 or G2 NET and a less aggressive non-neuroendocrine component, i.e. adenoma [6]. The latter has mainly been described in the stomach [25, 26], ileum [27], and colon/rectum [28, 29].

Overall, with the exclusion of the low-grade neoplasms, MiNEN are generally highly aggressive neoplasms with poor prognosis and thus should be managed as non-neuroendocrine cancers rather than classical NEN. Finally, the degree of differentiation of a "pure" non-neuroendocrine neoplasm component may have a prognostic implication (for example, in gastric, pancreatic, or colonic adenocarcinoma, or oesophageal squamous-cell carcinoma) but with no or limited therapeutic consequences. Similarly, it appears to be irrelevant in MiNEN and is not part of the proposed grade classification $[6,12]$.

\section{Organ-Specific Features and Prognosis}

MiNEN usually originate from organs that contain neuroendocrine cells and in which "classical" NENs are known to develop, such as pancreas, appendix, colon, and to a lesser degree small intestine $[3,7,12]$.

\section{Oesophagus}

MiNEN usually develop in the lower third portion of the oesophagus and are highly malignant $[6,12]$. Rare cases of amphicrine MiNEN with multiple differentiation phenotypes (adenocarcinoma, neuroendocrine and squamous-cell carcinoma) have been reported [7]. In a series of 40 patients with oesophageal PDNEC, an adenocarcinoma or squamous-cell carcinoma component was found in 38 and $3 \%$ of cases, respectively [30]. MiNEN were less frequently metastatic than "pure" PDNEC (25 vs. 54\%, $p=0.036$ ), and patient survival was better (28 vs. 15 months, $p=0.031$ ).

Conversely, a focal neuroendocrine component can be found in $8 \%$ of oesophageal adenocarcinomas, and could be associated with a more favourable tumour stage, but similar survival [13].

\section{Stomach}

Gastric MiNEN account for approximately $7 \%$ of all gastric NEN and 25\% of all gastric PDNEC, although their prevalence has not been specifically explored [14, $20,31]$. They are usually highly malignant and combine a well-differentiated adenocarcinoma and a PDNEC component, the latter commonly developing from deeper layer of the gastric wall $[6,12,32,33]$. In fact, some studies from Asian countries reported that nearly $70 \%$ of gastric PDNEC contained at least a minor adenocarcinoma component $[31,34]$. Should this be confirmed and replicated in Western countries, it would question the existence of true "pure" PDNEC of the stomach, which might all be associated with adenocarcinoma. Intermediate-grade MiNEN combining type 1 gastric NEN and adenocarcinoma have also been described, mainly in the setting of chronic atrophic gastritis [6].

Survival of patients with gastric MiNEN is similar or slightly better than that of patients with "pure" gastric PDNEC [14, 20, 31-33]. The threshold of 30\% for the PDNEC component in gastric MiNEN has been questioned $[14,33]$. In one series including 88 patients with non-metastatic MiNEN, the estimated cut-off above which the PDNEC component negatively influenced prognosis was $10 \%$ [14]. Indeed, the 5-year survival rates of patients treated for a gastric adenocarcinoma were 86 and $53 \%$ if they contained less or more than $10 \%$ of a PDNEC component, respectively $(p<0.0001)$. Conversely, there was no difference in survival among all neoplasms with a PDNEC component accounting for $>10 \%$, including in patients with "pure" PDNEC, regardless of the extent [14]. Hence, although this warrants confirmation studies and validation in Western population, it underlines that the current $30 \%$ arbitrary threshold may have insufficient prognostic value, and irrelevant therapeutic consequences.

\section{Pancreas}

Pancreatic MiNEN represent $0.5 \%$ of all pancreatic adenocarcinomas [10] and 5\% of all pancreatic NEN [35]. Their diagnosis is limited by a sampling bias due to the small samples obtained using endoscopic ultrasound-
416

Neuroendocrinology 2017;105:412-425 DOI: $10.1159 / 000475527$ de Mestier et al. 
guided fine-needle aspiration [36-38]. The neuroendocrine component is usually a large-cell type PDNEC, but can occasionally be a well-differentiated G1 or G2 NET $[12,39]$. When the neuroendocrine component is well differentiated, a hormone secretory syndrome may occur similarly to "pure" pancreatic NET $[40,41]$. The non-neuroendocrine component may have a ductal or acinar phenotype. Although association of intraductal papillary mucinous neoplasms and NET might not always be random $[42,43]$, true MiNEN with both of these components are very rare but do exist $[44,45]$. Of note, $40-80 \%$ of pancreatic adenocarcinomas entrap neuroendocrine islets, which may lead to over-diagnosing MiNEN (Fig. 2d) [10, 46, 47]. Similarly, 5-10\% of pancreatic NEN may entrap non-neoplastic ductules, and these "ductuloinsular" NEN should not been mistakenly diagnosed as MiNEN [10, 48, 49]. The prognosis of pancreatic MiNEN is intermediate between pure adenocarcinoma and pure G1-G2 NET [38, 39], and similar to that of "pure" PDNEC [35, 39, 50].

Pancreatic acinar-cell type carcinoma is rare (1-2\%). It contains a neuroendocrine component accounting for $>30$ or $<30 \%$ of the neoplasm in 30 and $15-30 \%$ of cases, respectively [50]. Both components can coexist separately, or form composite MiNEN with intermingled cell populations, whose morphological identification may be difficult but facilitated by immunohistochemical evidence of neuroendocrine (chromogranin-synaptophysin) and acinar (Bcl-10) components (Fig. 2c) [10, 38, 45, 50]. The presence of a neuroendocrine component in an acinar-cell carcinoma could improve its prognosis [51].

\section{Biliary Tract and Gallbladder}

MiNEN arising from extrahepatic bile ducts and the gallbladder account for 5 and 35\%, respectively, of all cholangiocarcinomas and NEN of these primary sites [52, 53]. Conversely, intra-hepatic biliary MiNEN are extremely rare [12]. These neoplasms are generally composed of PDNEC and pleomorphic adenocarcinoma [12]. The median overall survival of patients affected (12.2 months) appears to be slightly better than those with "pure" biliary PDNEC (9.6 months) [52, 53].

\section{Duodenum and Ampulla of Vater}

MiNEN can develop in the duodenum and often combine an intestinal-phenotype adenocarcinoma with a well-differentiated somatostatin-secreting NET. They are mostly superficial, not highly aggressive, and distant spreading is rare [7].

Some 30 cases of ampullary MiNEN have been reported in the literature $[52,54,55]$. The neuroendocrine com- ponent is usually located in the deepest layers; thus, most lesions are misdiagnosed as adenocarcinoma before surgical resection [55]. Half of ampullary MiNEN have an intermediate grade of malignancy, combining well-differentiated G1-G2 NET and adenocarcinoma components that generally have an intestinal phenotype with a better prognosis than bilio-pancreatic phenotype.

\section{Small Intestine}

MiNEN originating from the jejunum and ileum are rare. They usually include a well-differentiated NET associated with an adenoma or adenocarcinoma component, with an intermediate grade of malignancy $[4,6]$. MiNEN with a PDNEC component are exceptional, like "pure" PDNEC from these primary sites.

\section{Appendix}

Appendicular MiNEN, previously called "adenocarcinoid tumours," account for about $10 \%$ of all appendicular malignancies [56]. They usually involve both adenoma and well-differentiated neuroendocrine components, explaining the usually intermediate or low grade of malignancy. Most appendicular MiNEN are discovered at the systematic pathological examination of resected surgical specimens in patients operated on for an acute appendicitis, although $20-30 \%$ are identified incidentally [5759]. Their prognosis is much worse than that of "pure" appendicular well-differentiated NEN and rather close to that of adenocarcinoma, depending on the rate of adenocarcinoma component and the presence of signet-ring adenocarcinoma [56-61]. Indeed, in a recent analysis of the SEER database, median overall survival for patients with appendix MiNEN was 6.5 years, while it was 2.1, 13.8 , and 39.4 years for those with signet-ring cell carcinoma, goblet-cell carcinoid and typical NET [56].

Besides, "goblet-cell carcinoids" are caliciform-type neoplasms that include mucus-secreting cells developing from the submucosa, with signet-ring cell morphology. Although they can have scattered neuroendocrine differentiation, they may rather be considered peculiar adenocarcinoma arising from the "appendicular glands" and should not be classified as NEN [6, 60]; thus, detailed description will not be provided herein. Finally, tubulartype appendicular carcinoids are not MiNEN but lowgrade NET with glandular architecture.

\section{Colon and Rectum}

Colorectal MiNEN are among the most frequent types of MiNEN. "Pure" NET and MiNEN accounted for 1.1 and $2.4 \%$ of 988 surgically resected colorectal neoplasms, 


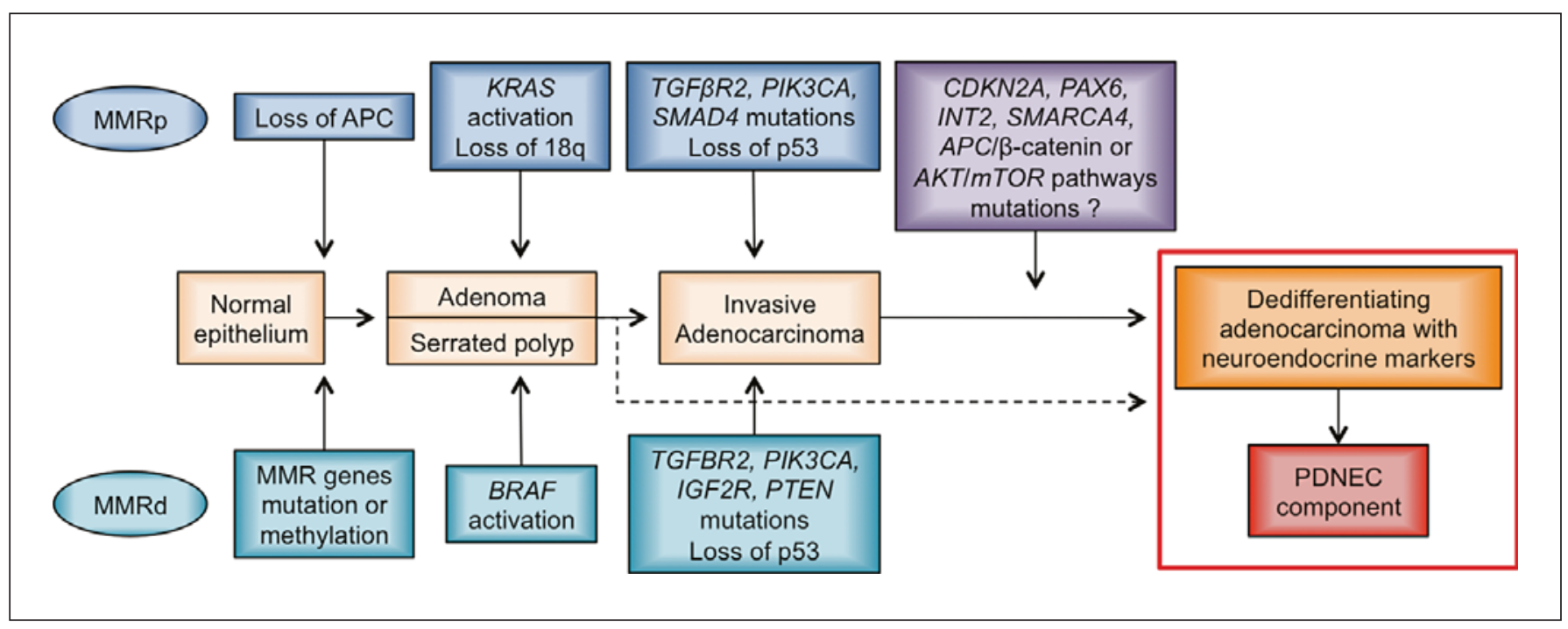

Fig. 3. Hypothesis of colorectal MiNEN development during the adenoma-adenocarcinoma multi-step sequence. The PDNEC component of colorectal MiNEN harbours additional molecular alterations in addition to those shared with their associated adenocarcinoma/adenoma component, such as mutations in the CDKN2A, PAX6, SMARCA4, or INT2 genes, those encoding for

respectively [62]. Rectal MiNEN only accounted for 1-3\% of rectal NEN, while colonic MiNEN represent $14-20 \%$ of colonic NEN $[63,64]$.

Most colonic NEN (85\%) are PDNEC, which contain a non-neuroendocrine component in $25-40 \%$ of cases $[21,65-68]$. The latter is usually an adenocarcinoma, but adenoma or squamous-cell carcinoma is found in about $45-65,30-35 \%$, and $5 \%$ of cases, respectively, mostly arising from the mucosa, while the neuroendocrine component frequently develops from deeper layer of the colon wall and may be missed when no further resection of the primary tumour is performed following biopsies.

The prognosis of colorectal MiNEN is worse than that of "pure" adenocarcinoma, and closer to that of PDNEC, especially at metastatic stage $[21,63]$. The metastatic risk seems correlated to the grade of the neuroendocrine component [66]. Accordingly, when the latter is a PDNEC, it is almost always present in metastases, while the adenocarcinoma is only present in about $30 \%$ of cases [66]. When the neuroendocrine component is well-differentiated, the type of cell population in the metastases is difficult to predict and does not always correspond to the most aggressive or most prevalent component in the primary tumour [66].

Finally, approximately $5 \%$ of colorectal MiNEN have a low grade of malignancy, combining tubulous or villous proteins of the $A P C / \beta$-catenin pathway, or those involved in the AKT/mTOR pathway. Inspired by the colorectal carcinogenesis sequence proposed by Vilar and Gruber [98]. MMRp, mismatch repair proficient; MMRd, mismatch repair deficient; PDNEC, poorly differentiated neuroendocrine tumour.

adenoma with G1-G2 NET. They usually present as polyps $<3 \mathrm{~cm}$ in diameter and can occasionally cause a carcinoid syndrome $[6,66,69]$.

\section{Pathogenesis and Molecular Findings}

The carcinogenesis of MiNEN has still not been elucidated, due in part to the lack of preclinical models. Although common origin and precursor may be suggested by amphicrine MiNEN [8], this is less evident for collision or composite MiNEN [6]. Molecular studies uniformly reported that when the neuroendocrine component is poorly differentiated, it shares similar genomic abnormalities than the adenocarcinoma component which supports a common origin, whatever the site of primary. Regardless the methodology used (including SNP chips and next generation sequencing), the two components display loss of heterozygosity ( $\mathrm{LOH})$ at multiple loci and mutations in key oncogenes, such as the APC, TP53, or $R B$ genes [34, 66, 67, 70-74]. These studies also showed that the PDNEC component contains additional mutations compared to the adenocarcinoma counterpart (Fig. 3) [66, 70-75].

Besides, radiotherapy and chemotherapy might favour genomic instability and transdifferentiation towards the de Mestier et al. 
PDNEC component, based on observations that the number of neuroendocrine markers-positive cells increased following neo-adjuvant treatments $[18,65]$. This strongly suggests that the PDNEC component develops during a classic adenoma-adenocarcinoma sequence. Such event can occur at various stages, including early stages such as adenoma, since cases of MiNEN combining PDNEC and adenoma, without adenocarcinoma, have been reported (Fig. 3) [66, 71].

PDNEC mutational signature seems more specific of their primary locations and similar to that of adenocarcinomas of same site, rather than a common neuroendocrine signature $[66,67,70-73,75-77]$. For instance, the molecular study of 867 PDNEC of various origins showed that $C D K N 2 A / B$ and $A P C$ mutations were present in 27 and $3 \%$ of pancreatic PDNEC (28.3 and $2.5 \%$ in pancreatic adenocarcinomas [78]), respectively, compared to 6 and $47 \%$ of colon PDNEC (9.8 and $49.3 \%$ in colon adenocarcinomas [78]), respectively [79]. In addition, 10-15\% of PDNEC and MiNEN originating from colon, rectum, or stomach have a mismatch repair-deficient phenotype $[21,24,75,80]$. These neoplasms have an increased methylation profile and prolonged survival, similar to what is observed in elderly patients with sporadic colorectal adenocarcinoma and mismatch repair deficiency due to the methylation of promoter of specific genes, which supports a common carcinogenic pathway between PDNEC/ MiNEN and adenocarcinoma. It could be possible that these patients with such mismatch repair-deficient metastatic MiNEN might benefit from immunotherapy; accumulating evidence shows that this is possible in those with colorectal adenocarcinoma [81].

Conversely, well-differentiated NET components of MiNEN do not harbour similar genetic alterations described in the adenoma/adenocarcinoma counterpart, such as $\mathrm{LOH}$ of $A P C, K R A S$, and TP53, but display specific alterations that are usually found in NET (but not PDNEC), such as LOH of $V H L[66,72,80]$. Although these low-grade MiNEN may indicate an earlier stage of carcinogenesis, they may also represent true collision MiNEN with an independent carcinogenic pathway.

\section{Management of MiNEN}

The treatment of MiNEN has not been codified yet due to their rarity and heterogeneity. Figures 4 and 5 show our suggestions for the management of both non-metastatic and metastatic MiNEN, respectively. Generally, aggressiveness and prognosis are driven by the most aggressive

Mixed Neuroendocrine-Non-

Neuroendocrine Neoplasms neoplastic component $[3,4,6,7]$. In localized MiNEN of the digestive tract, endoscopy-guided tumour biopsies may not reach the neuroendocrine component for the reasons exposed before, thus potentially leading to its under-diagnosis.

The treatment of metastatic MiNEN should logically target the neoplastic component responsible for the metastatic spreading rather than rely on the characteristics of the primary, since the neuroendocrine and non-neuroendocrine components can metastasize together but also separately, even in collision MiNEN [82]. Nevertheless, metachronous metastases are rarely biopsied, and nuclear medicine tools cannot help distinguishing between adenocarcinoma and PDNEC because, for example, both components display ${ }^{18} \mathrm{FDG}$ positron-emitting tomography positivity, and negative somatostatin receptor scintigraphy due to lack of somatostatin receptors expression [83]. The cell type present in tumour emboli on resected primary tumours may be similar to that found in lymph node and distant metastases; thus, its analysis could be an alternative to metastasis biopsy [22].

\section{High-Grade MiNEN}

The prognosis of localized high-grade MiNEN is better than that of "pure" PDNEC. Similarly, they should be treated by curative-intent surgery whenever feasible [84]. Surgical resection of localized pancreatic MiNEN containing acinar-cell carcinoma might improve survival $[50,63,66]$. The potential benefit of adjuvant treatments following resection of localized MiNEN is still undefined, although some retrospective data have suggested a favourable effect [24, 30, 38, 39, 68, 85].

Like in "pure" PDNEC and adenocarcinoma, the benefit/risk ratio does not seem to support performing extensive surgical resection in locally advanced MiNEN [63, 84]. The first-intent treatment of an advanced disease should include systemic chemotherapy combining etoposide and a platinum salt by analogy with PDNEC, and notably because the expression of ERCC1 (protein repairing the DNA damages caused by platinum salts) may be stronger in MiNEN than in adenocarcinoma of same location [24]. Upon progression, the first-line etoposideplatinum regimen could be reintroduced if this disease is controlled without chemotherapy for $>3$ months [84]. Otherwise, the use of combinations of 5-fluorouracil and irinotecan or temozolomide $[63,84]$ or amrubicin has been suggested [86-88]. Limited data reported that somatostatin receptor (SSTR2) expression was very uncommon in gastric (0/8) [20], colon (0/8) [68], or biliary (2/9) [53] high-grade MiNEN. Hence, long-acting somatosta-

Neuroendocrinology 2017;105:412-425 419 


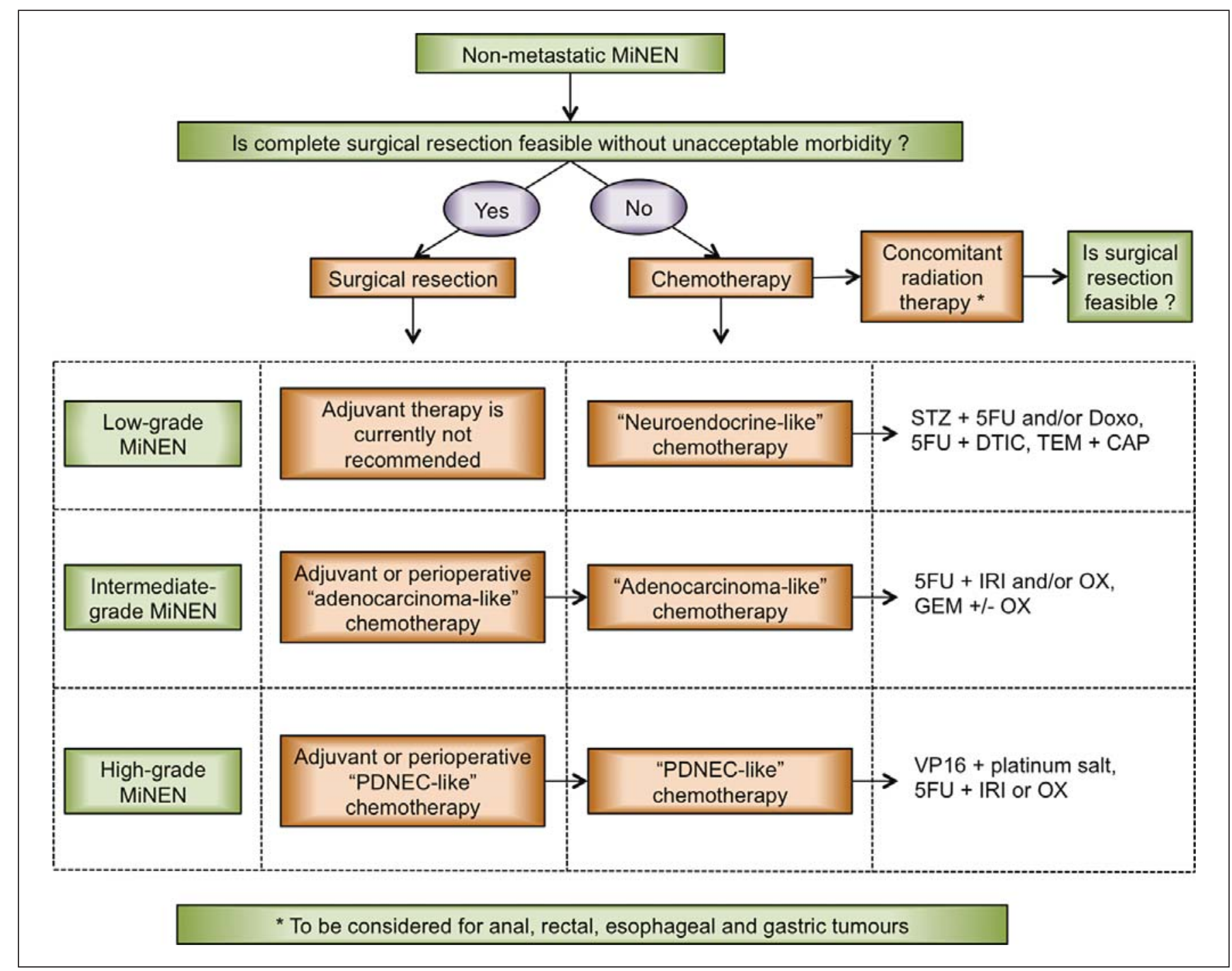

Fig. 4. Proposal for standardization of the management of nonmetastatic MiNEN. The mainstay of treatment of non-metastatic MiNEN and the only chance of cure remains surgical resection. If an adjuvant treatment is indicated, or if the neoplasm is not resectable, the type of chemotherapy depends on the grade of malignan-

tin analogues or peptide-radionuclide radiation therapy must not be used in high-grade MiNEN, similarly to "pure" NEC.

When metastases contain a prominent adenocarcinoma component, which is rare because the PDNEC is almost always - at least in part - present in metastases, treatment should be similar to that given for "pure" adenocarcinomas [63]. cy of each component. 5FU, 5-fluorouracil; Doxo, doxorubicin; DTIC, dacarbazine; GEM, gemcitabine; IRI, irinotecan; OX, oxaliplatin; STZ, streptozotocin; TEM, temozolomide; VP16, etoposide.

\section{Intermediate-Grade MiNEN}

Like in high-grade MiNEN, curative-intent resection of localized disease should be proposed whenever possible, followed by adjuvant chemotherapy depending on the pathological factors of relapse $[61,63,68,84]$. In case of metastases, primary tumour resection can be discussed, when symptomatic, following organ-specific cancer guidelines (mainly for colorectal neoplasms). Systemic chemotherapy regimens should be tailored based on a panel of agents that have shown to be effective in both digestive adenocarcinomas and NET (Fig. 4, 5). 


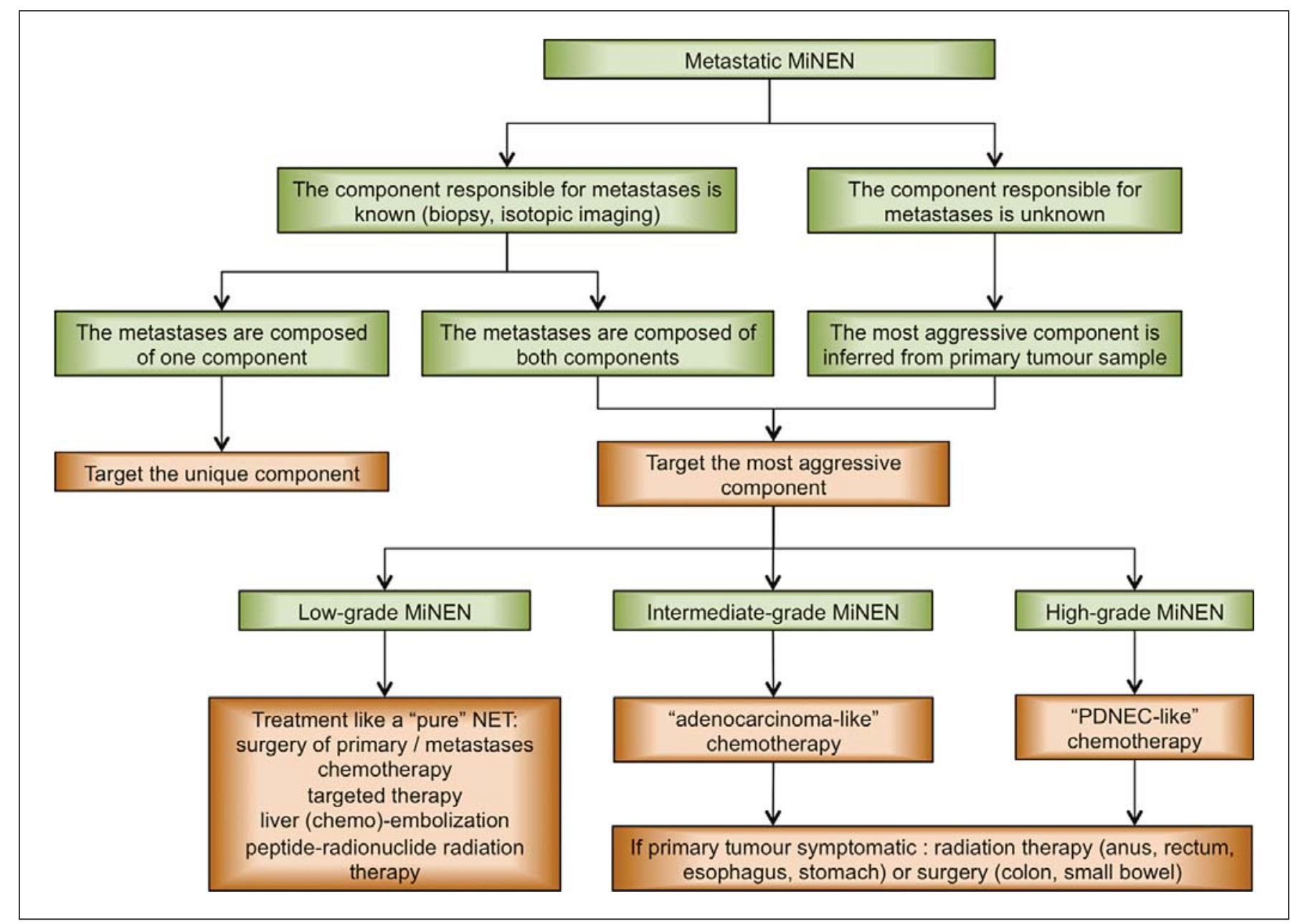

Fig. 5. Proposal for standardization of management of metastatic MiNEN. The treatment should target the components present within the metastases, depending on their respective grades of malignancy.

\section{Low-Grade MiNEN}

Since these neoplasms combine adenoma and welldifferentiated G1-G2 NET components, the prognosis is driven by the latter component as it can metastasize, and thus should be the targeted. Localized tumours should be surgically resected, or endoscopically for those located within an accessible site of the gastrointestinal tract $[6,66$, 89]. For locally advanced tumours, a curative-intent surgical resection with lymphadenectomy should be performed. Treatment in the rare cases of metastatic forms, which usually originate from the NET component, should be similar to that of "pure NET" of the same origin based on current guidelines $[90,91]$. Especially, metastatic lowgrade MiNEN (and metastatic intermediate-grade MiNEN with predominant NET component) frequently express type 2 somatostatin receptors (SSTR2) and could be treated with long-acting somatostatin analogues $[92,93]$ and/or peptide-radionuclide radiation therapy [94], since survival benefit was demonstrated in "pure" NET with these treatments. For the same reasons, everolimus could be useful in these patients $[95,96]$, although the frequent mutations of the Akt/mTOR pathway seen in "pure" NET have not been specifically explored in MiNEN [97].

\section{Conclusion}

The grade of MiNEN depends on the metastatic and life-threatening potential of each component. The most common forms combine adenocarcinoma and PDNEC components, with prognosis being intermediate between that of "pure" adenocarcinoma and that of "pure" 
PDNEC of same origin. Therapeutic management should be based on the most aggressive neoplastic component, which can only be reliably determined by the analysis of a resected specimen, even if it accounts for less than 30\% of the neoplasm.

The unresolved question about the existence of "pure" PDNEC should be further explored. Future research should confirm whether the PDNEC component of MiN$\mathrm{EN}$ is a result of additional genomic alterations in an adenocarcinoma; otherwise, to identify the pathogenic pathways involved in this carcinogenic "turning point" is strongly needed, in particular using whole-genome sequencing. More accessible genomic material should be studied, such as circulating tumour cells or DNA; these liquid biopsies could be an innovative approach to more broadly characterize the genetic landscape of MiNEN. Finally, the minimum percentage from which each neoplastic component has a prognostic impact must be specified (and especially in biopsy samples, which do not take neoplasm heterogeneity into account, in contrast to surgical specimens), in order to determine which patients may benefit from the most targeted treatment.

\section{Acknowledgements}

The authors thank Mrs. Dale Roche-Lebrec for technical assistance in the preparation of the manuscript (funded by the Association Robert Debré pour la Recherche Médicale).

\section{Disclosure Statement}

All authors declare no potential conflict of interest in relation to this study.

\section{Author Contributions}

Study concept and design: L.M., J.C., P.H. Acquisition of data: L.M., J.C., C.N., P.H. Analysis and interpretation of data: L.M., J.C., C.N., O.H., N.M., G.C., P.R., A.C., O.B., P.H. Drafting of the manuscript: L.M., J.C., C.N., A.C., O.B., P.H. Critical revision of the manuscript for important intellectual content: L.M., J.C., C.N., O.H., N.M., G.C., P.R., A.C., O.B., P.H. Study supervision: L.M., G.C., P.R., A.C., O.B., P.H.

\section{References}

1 Lepage C, Bouvier AM, Faivre J: Endocrine tumours: epidemiology of malignant digestive neuroendocrine tumours. Eur J Endocrinol 2013;168:R77-R83.

2 Klöppel G, Couvelard A, Hruban RH, Klimstra DS, Komminoth P, Osamura RY, et al: Neoplasms of the neuroendocrine pancreas; in: WHO Classification of Tumours of the Endocrine Organs, ed 4. Lyon, IARC Press, 2017, pp 210-239.

3 Volante M, Rindi G, Papotti M: The grey zone between pure (neuro)endocrine and non(neuro)endocrine tumours: a comment on concepts and classification of mixed exocrine-endocrine neoplasms. Virchows Arch 2006;449:499-506.

4 Volante M, Righi L, Asioli S, Bussolati G, Papotti M: Goblet cell carcinoids and other mixed neuroendocrine/nonneuroendocrine neoplasms. Virchows Arch 2007;451:61-69.

5 Lewin K: Carcinoid tumors and the mixed (composite) glandular-endocrine cell carcinomas. Am J Surg Pathol 1987;11(suppl 1):71-86.

6 La Rosa S, Marando A, Sessa F, Capella C: Mixed adenoneuroendocrine carcinomas (MANECs) of the gastrointestinal tract: an update. Cancers 2012;4:11-30.

7 Hervieu V, Scoazec J-Y: Mixed endocrine tumors (in French). Ann Pathol 2005;25:511528.
8 Gravante G, Yahia S, Gopalakrishnan K, Mathew G: Goblet cells carcinoid with mucinous adenocarcinoma of the vermiform appendix: a step towards the unitary intestinal stem cell theory? Eur Rev Med Pharmacol Sci 2014;18:1591-1594.

9 Ludmir EB, McCall SJ, Cardona DM, Perkinson KR, Guy CD, Zhang X: Mixed adenoneuroendocrine carcinoma, amphicrine type, of the small bowel. Am J Clin Pathol 2016;145: 703-709.

10 Reid MD, Akkas G, Basturk O, Adsay V: Mixed adenoneuroendocrine carcinoma of the pancreas; in La Rosa S, Sessa F (eds): Pancreatic Neuroendocrine Neoplasms. Cham, Springer, 2015, pp 155-165.

11 Rindi G, Klimstra DS, Arnold R, Klöppel G, Bosman FT, Komminoth P, et al: Nomenclature and classification of neuroendocrine neoplasms of the digestive system; in WHO Classification of Tumours of the Digestive System, ed 4. Lyon, IARC Press, 2010, pp 1314.

12 La Rosa S, Sessa F, Uccella S: Mixed neuroendocrine-nonneuroendocrine neoplasms (MiNENs): unifying the concept of a heterogeneous group of neoplasms. Endocr Pathol DOI: $10.1007 / \mathrm{s} 12022-016-9432-9$.
13 Koppert LB, Wijnhoven BPL, Tilanus HW, Stijnen T, Van Dekken H, Dinjens WNM: Neuroendocrine in Barrett's mucosa and adenocarcinomas of the gastroesophageal junction. Int J Surg Pathol 2004;12:117-125.

14 Park JY, Ryu M-H, Park YS, Park HJ, Ryoo B-Y, Kim MG, et al: Prognostic significance of neuroendocrine components in gastric carcinomas. Eur J Cancer 2014;50:2802-2809.

15 Naritomi K, Futami K, Arima S, Iwashita A: Malignant potential regarding mucin phenotypes and endocrine cell differentiation in gastric adenocarcinoma. Anticancer Res 2003;23:4411-4422.

16 Canzonieri V, Colarossi C, Del Col L, Perin T, Talamini R, Sigon R, et al: Exocrine and endocrine modulation in common gastric carcinoma. Am J Clin Pathol 2012;137:712-721.

17 Hong S-M, Kim M-J, Pi DY, Jo D, Yu E, Ro JY: Neuroendocrine differentiation in extrahepatic bile duct carcinomas and its prognostic significance. Hum Pathol 2005;36:732740.

18 Volante M, Marci V, Andrejevic-Blant S, Tavaglione V, Sculli MC, Tampellini M, et al: Increased neuroendocrine cells in resected metastases compared to primary colorectal adenocarcinomas. Virchows Arch Int J Pathol 2010;457:521-527.

19 Kleist B: Neuroendocrine differentiation: the mysterious fellow of colorectal cancer. World J Gastroenterol 2015;21:11740. 
20 La Rosa S, Inzani F, Vanoli A, Klersy C, Dainese L, Rindi G, et al: Histologic characterization and improved prognostic evaluation of 209 gastric neuroendocrine neoplasms. Hum Pathol 2011;42:1373-1384.

21 La Rosa S, Marando A, Furlan D, Sahnane N, Capella C: Colorectal poorly differentiated neuroendocrine carcinomas and mixed adenoneuroendocrine carcinomas: insights into the diagnostic immunophenotype, assessment of methylation profile, and search for prognostic markers. Am J Surg Pathol 2012; 36:601-611.

22 Chen M-H, Kuo Y-J, Yeh Y-C, Lin Y-C, Tzeng C-H, Liu C-Y, et al: High neuroendocrine component is a factor for poor prognosis in gastrointestinal high-grade malignant mixed adenoneuroendocrine neoplasms. J Chin Med Assoc 2015;78:454-459.

23 Brenner B, Shah MA, Gonen M, Klimstra DS, Shia J, Kelsen DP: Small-cell carcinoma of the gastrointestinal tract: a retrospective study of 64 cases. Br J Cancer 2004;90:1720-1726.

24 Volante M, Monica V, Birocco N, Brizzi MP, Busso S, Daniele L, et al: Expression analysis of genes involved in DNA repair or synthesis in mixed neuroendocrine/nonneuroendocrine carcinomas. Neuroendocrinology 2015; 101:151-160.

25 Coyne JD, O'Connor B: Mixed adenoma-endocrine tumour of the stomach. Histopathology 2010;57:492-494.

26 Lee S-M, Ahn S, Lee YK, Jang K-T, Park CK, Kim K-M: Neuroendocrine tumor in gastric adenoma: a diagnostic pitfall mimicking invasive adenocarcinoma. Diagn Pathol 2012;7: 102.

27 Varghese NM, Zaitoun AM, Thomas SM, Senapati A, Theodossi A: Composite glandularcarcinoid tumour of the terminal ileum. J Clin Pathol 1994;47:427-429.

28 Moyana TN, Qizilbash AH, Murphy F: Composite glandular-carcinoid tumors of the colon and rectum. Report of two cases. Am J Surg Pathol 1988;12:607-611.

29 Lyda MH, Fenoglio-Preiser CM: Adenomacarcinoid tumors of the colon. Arch Pathol Lab Med 1998;122:262-265.

30 Maru DM, Khurana H, Rashid A, Correa AM, Anandasabapathy S, Krishnan S, et al: Retrospective study of clinicopathologic features and prognosis of high-grade neuroendocrine carcinoma of the esophagus. Am J Surg Pathol 2008;32:1404-1411.

31 Ishida M, Sekine S, Fukagawa T, Ohashi M, Morita S, Taniguchi $\mathrm{H}$, et al: Neuroendocrine carcinoma of the stomach: morphologic and immunohistochemical characteristics and prognosis. Am J Surg Pathol 2013;37:949959.

32 Rayhan N, Sano T, Qian ZR, Obari AK, Hirokawa M: Histological and immunohistochemical study of composite neuroendocrine-exocrine carcinomas of the stomach. J Med Investig 2005;52:191-202.
33 Jiang S-X, Mikami T, Umezawa A, Saegusa M, Kameya T, Okayasu I: Gastric large cell neuroendocrine carcinomas: a distinct clinicopathologic entity. Am J Surg Pathol 2006;30: 945-953.

34 Nishikura K, Watanabe H, Iwafuchi M, Fujiwara T, Kojima K, Ajioka Y: Carcinogenesis of gastric endocrine cell carcinoma: analysis of histopathology and p53 gene alteration. Gastric Cancer Off J Int Gastric Cancer Assoc Jpn Gastric Cancer Assoc 2003;6:203-209.

35 Yang M, Ke N, Zhang Y, Zeng L, Tan C, Zhang $\mathrm{H}$, et al: Survival analyses for patients with surgically resected pancreatic neuroendocrine tumors by World Health Organization 2010 Grading Classifications and American Joint Committee on Cancer 2010 Staging Systems. Medicine (Baltimore) 2015;94: e2156.

36 Kaji K, Seishima J, Yamato M, Miyazawa M, Komura T, Marukawa Y, et al: Clinical utility of endoscopic ultrasound-guided fine-needle aspiration in mixed adenoneuroendocrine carcinoma with signet-ring cells of the pancreas: a case report and review of the literature. Clin J Gastroenterol 2016;9:43-48.

37 Sullivan PS, Clebanoff JL, Hirschowitz SL: Hints to the diagnosis of mixed acinar-endocrine carcinoma on pancreatic fine-needle aspiration: avoiding a potential diagnostic pitfall. Acta Cytol 2013;57:296-302.

38 Yu R, Jih L, Zhai J, Nissen NN, Colquhoun S, Wolin E, et al: Mixed acinar-endocrine carcinoma of the pancreas: new clinical and pathological features in a contemporary series. Pancreas 2013;42:429-435.

39 Basturk O, Tang L, Hruban RH, Adsay V, Yang Z, Krasinskas AM, et al: Poorly differentiated neuroendocrine carcinomas of the pancreas: a clinicopathologic analysis of 44 cases. Am J Surg Pathol 2014;38:437-447.

40 Ballas KD, Rafailidis SF, Demertzidis C, Alatsakis MB, Pantzaki A, Sakadamis AK: Mixed exocrine-endocrine tumor of the pancreas. JOP J Pancreas 2005;6:449-454.

41 Hirano H, Terada N, Yamada N, Yamanegi Y, Oyama H, Nishigami T, et al: A case of mixed ductal-endocrine carcinoma of the pancreas. Med Mol Morphol 2011;44:58-62.

42 Marrache F, Cazals-Hatem D, Kianmanesh R, Palazzo L, Couvelard A, O’Toole D, et al: Endocrine tumor and intraductal papillary mucinous neoplasm of the pancreas: a fortuitous association? Pancreas 2005;31:79-83.

43 Kadota Y, Shinoda M, Tanabe M, Tsujikawa $\mathrm{H}$, Ueno A, Masugi $Y$, et al: Concomitant pancreatic endocrine neoplasm and intraductal papillary mucinous neoplasm: a case report and literature review. World J Surg Oncol 2013;11:1.

44 Hashimoto Y, Murakami Y, Uemura K, Hayashidani $Y$, Sudo T, Ohge H, et al: Mixed ductal-endocrine carcinoma derived from intraductal papillary mucinous neoplasm (IPMN) of the pancreas identified by human telomerase reverse transcriptase (hTERT) expression. J Surg Oncol 2008;97:469-475.
45 Chang S-M: Solitary concomitant endocrine tumor and ductal adenocarcinoma of pancreas. World J Gastroenterol 2010;16:2692.

46 Sakaki M, Sano T, Hirokawa M, Takahashi M, Kiyoku H: Immunohistochemical study of endocrine cells in ductal adenocarcinoma of the pancreas. Virchows Arch Int J Pathol 2002;441:249-255.

47 Ohike N, Jürgensen A, Pipeleers-Marichal M, Klöppel G: Mixed ductal-endocrine carcinomas of the pancreas and ductal adenocarcinomas with scattered endocrine cells: characterization of the endocrine cells. Virchows Arch Int J Pathol 2003;442:258-265.

48 van Eeden S, de Leng WWJ, Offerhaus GJA, Morsink FH, Weterman MAJ, de Krijger RR, et al: Ductuloinsular tumors of the pancreas: endocrine tumors with entrapped nonneoplastic ductules. Am J Surg Pathol 2004;28: 813-820.

49 Deshpande V, Selig MK, Nielsen GP, Fernandez-del Castillo C, Lauwers GY: Ductulo-insular pancreatic endocrine neoplasms: clinicopathologic analysis of a unique subtype of pancreatic endocrine neoplasms. Am J Surg Pathol 2003;27:461-468.

50 La Rosa S, Adsay V, Albarello L, Asioli S, Casnedi S, Franzi F, et al: Clinicopathologic study of 62 acinar cell carcinomas of the pancreas: insights into the morphology and immunophenotype and search for prognostic markers. Am J Surg Pathol 2012;36:17821795.

51 Machado MCC, Machado MAC, Perini MV, Herman P, Jukemura J, Leite KR, et al: Acinar cell carcinoma of the pancreas: is the absence of neuroendocrine component related to a more malignant behavior? Hepatogastroenterology 2008;55:708-710.

52 Kim J, Lee WJ, Lee SH, Lee KB, Ryu JK, Kim Y-T, et al: Clinical features of 20 patients with curatively resected biliary neuroendocrine tumours. Dig Liver Dis 2011;43:965-970.

53 Harada K, Sato Y, Ikeda H, Maylee H, Igarashi S, Okamura A, et al: Clinicopathologic study of mixed adenoneuroendocrine carcinomas of hepatobiliary organs. Virchows Arch 2012; 460:281-289.

54 Adsay V, Ohike N, Tajiri T, Kim GE, Krasinskas A, Balci S, et al: Ampullary region carcinomas: definition and site specific classification with delineation of four clinicopathologically and prognostically distinct subsets in an analysis of 249 cases. Am J Surg Pathol 2012; 36:1592-1608.

55 Zhang L, DeMay RM: Cytological features of mixed adenoneuroendocrine carcinoma of the ampulla: two case reports with review of literature: cytological features of adenoneuroendocrine carcinoma. Diagn Cytopathol 2014;42:1075-1084.

56 Brathwaite S, Yearsley MM, Bekaii-Saab T, Wei L, Schmidt CR, Dillhoff ME, et al: Appendiceal mixed adeno-neuroendocrine carcinoma: a population-based study of the surveillance, epidemiology, and end results registry. Front Oncol 2016;6:148.
Mixed Neuroendocrine-Non-

Neuroendocrine Neoplasms
Neuroendocrinology 2017;105:412-425 DOI: $10.1159 / 000475527$ 
57 McCusker ME, Coté TR, Clegg LX, Sobin LH: Primary malignant neoplasms of the appendix: a population-based study from the surveillance, epidemiology and end-results program, 1973-1998. Cancer 2002;94:33073312.

58 McGory ML, Maggard MA, Kang H, O'Connell JB, Ko CY: Malignancies of the appendix: beyond case series reports. Dis Colon Rectum 2005;48:2264-2271.

59 Taggart MW, Abraham SC, Overman MJ, Mansfield PF, Rashid A: Goblet cell carcinoid tumor, mixed goblet cell carcinoid-adenocarcinoma, and adenocarcinoma of the appendix: comparison of clinicopathologic features and prognosis. Arch Pathol Lab Med 2015; 139:782-790.

60 Pape U-F, Perren A, Niederle B, Gross D, Gress T, Costa F, et al: ENETS Consensus Guidelines for the management of patients with neuroendocrine neoplasms from the jejuno-ileum and the appendix including goblet cell carcinomas. Neuroendocrinology 2012;95:135-156.

61 Brathwaite S, Rock J, Yearsley MM, BekaiiSaab T, Wei L, Frankel WL, et al: Mixed adeno-neuroendocrine carcinoma: an aggressive clinical entity. Ann Surg Oncol 2016;23: 2281-2286.

62 Saclarides TJ, Szeluga D, Staren ED: Neuroendocrine cancers of the colon and rectum. Results of a ten-year experience. Dis Colon Rectum 1994;37:635-642.

63 Smith JD, Reidy DL, Goodman KA, Shia J, Nash GM: A retrospective review of 126 highgrade neuroendocrine carcinomas of the colon and rectum. Ann Surg Oncol 2014;21: 2956-2962.

64 Kojima M, Ikeda K, Saito N, Sakuyama N, Koushi K, Kawano S, et al: Neuroendocrine tumors of the large intestine: clinicopathological features and predictive factors of lymph node metastasis. Front Oncol 2016;6:173.

65 Shia J, Tang LH, Weiser MR, Brenner B, Adsay NV, Stelow EB, et al: Is nonsmall cell type high-grade neuroendocrine carcinoma of the tubular gastrointestinal tract a distinct disease entity? Am J Surg Pathol 2008;32:719-731.

66 Li Y, Yau A, Schaeffer D, Magliocco A, Gui X, Urbanski S, et al: Colorectal glandular-neuroendocrine mixed tumor: pathologic spectrum and clinical implications. Am J Surg Pathol 2011;35:413-425.

67 Karkouche R, Bachet J-B, Sandrini J, Mitry E, Penna C, Côté J-F, et al: Colorectal neuroendocrine carcinomas and adenocarcinomas share oncogenic pathways. A clinico-pathologic study of 12 cases. Eur J Gastroenterol Hepatol 2012;24:1430-1437.

68 Komatsubara T, Koinuma K, Miyakura Y, Horie $\mathrm{H}$, Morimoto $\mathrm{M}$, Ito $\mathrm{H}$, et al: Endocrine cell carcinomas of the colon and rectum: a clinicopathological evaluation. Clin J Gastroenterol 2016;9:1-6.
69 Hui C-K: Collision adenoma-carcinoid tumour of the colon complicated by carcinoid syndrome. Singapore Med J 2012;53:e195e197.

70 Kim K-M, Kim M-J, Cho B-K, Choi S-W, Rhyu M-G: Genetic evidence for the multistep progression of mixed glandular-neuroendocrine gastric carcinomas. Virchows Arch Int J Pathol 2002;440:85-93.

71 Vortmeyer AO, Lubensky IA, Merino MJ, Wang CY, Pham T, Furth EE, et al: Concordance of genetic alterations in poorly differentiated colorectal neuroendocrine carcinomas and associated adenocarcinomas. J Natl Cancer Inst 1997;89:1448-1453.

72 Furlan D, Cerutti R, Genasetti A, Pelosi G, Uccella S, La Rosa S, et al: Microallelotyping defines the monoclonal or the polyclonal origin of mixed and collision endocrine-exocrine tumors of the gut. Lab Invest 2003;83: 963-971.

73 Scardoni M, Vittoria E, Volante M, Rusev B, Bersani S, Mafficini A, et al: Mixed adenoneuroendocrine carcinomas of the gastrointestinal tract: targeted next-generation sequencing suggests a monoclonal origin of the two components. Neuroendocrinology 2014;100: 310-316.

74 Vanacker L, Smeets D, Hoorens A, Teugels E, Algaba R, Dehou MF, et al: Mixed adenoneuroendocrine carcinoma of the colon: molecular pathogenesis and treatment. Anticancer Res 2014;34:5517-5521.

75 Furlan D, Sahnane N, Mazzoni M, Pastorino $\mathrm{R}$, Carnevali I, Stefanoli M, et al: Diagnostic utility of MS-MLPA in DNA methylation profiling of adenocarcinomas and neuroendocrine carcinomas of the colon-rectum. Virchows Arch 2013;462:47-56.

76 Woischke C, Schaaf CW, Yang H-M, Vieth M, Veits L, Geddert H, et al: In-depth mutational analyses of colorectal neuroendocrine carcinomas with adenoma or adenocarcinoma components. Mod Pathol 2017;30:95103.

77 Takizawa N, Ohishi Y, Hirahashi M, Takahashi S, Nakamura K, Tanaka M, et al: Molecular characteristics of colorectal neuroendocrine carcinoma; similarities with adenocarcinoma rather than neuroendocrine tumor. Hum Pathol 2015;46:1890-1900.

78 COSMIC database. http://cancer.sanger. ac.uk/cosmic (accessed online July 1st, 2016).

79 Bergsland EK, Roy R, Stephens P, Ross JS, Bailey M, Olshen A: Genomic profiling to distinguish poorly differentiated neuroendocrine carcinomas arising in different sites. ASCO Meet Abstr 2016;34:4020.

80 Sahnane N, Furlan D, Monti M, Romualdi C, Vanoli A, Vicari E, et al: Microsatellite unstable gastrointestinal neuroendocrine carcinomas: a new clinicopathologic entity. Endocr Relat Cancer 2015;22:35-45.

81 Le DT, Uram JN, Wang H, Bartlett BR, Kemberling $\mathrm{H}$, Eyring $\mathrm{AD}$, et al: $\mathrm{PD}-1$ blockade in tumors with mismatch-repair deficiency. N Engl J Med 2015;372:2509-2520.
82 Minaya-Bravo AM, Garcia Mahillo JC, Mendoza Moreno F, Noguelares Fraguas F, Granell J: Large cell neuroendocrine - adenocarcinona mixed tumour of colon: collision tumour with peculiar behaviour. What do we know about these tumours? Ann Med Surg 2015;4:399-403.

83 Lim SM, Kim H, Kang B, Kim HS, Rha SY, Noh SH, et al: Prognostic value of 18F-fluorodeoxyglucose positron emission tomography in patients with gastric neuroendocrine carcinoma and mixed adenoneuroendocrine carcinoma. Ann Nucl Med 2016;30:279-286.

84 Sorbye H, Strosberg J, Baudin E, Klimstra DS, Yao JC: Gastroenteropancreatic high-grade neuroendocrine carcinoma. Cancer 2014; 120:2814-2823.

85 Juanmartiñena JF, Fernández-Urien I, Córdoba A, Miranda Murua C, Borda A: Mixed adenoneuroendocrine carcinoma (MANEC) of the gastroesophageal junction: a case report and review of the literature. Rev Esp Enferm Dig 2017;109:160-162.

86 Ando T, Hosokawa A, Yoshita H, Ueda A, Kajiura S, Mihara H, et al: Amrubicin monotherapy for patients with platinum-refractory gastroenteropancreatic neuroendocrine carcinoma. Gastroenterol Res Pract 2015;2015:1-5.

87 Asayama M, Fuse N, Yoshino T, Yano T, Tahara M, Doi T, et al: Amrubicin for the treatment of neuroendocrine carcinoma of the gastrointestinal tract: a retrospective analysis of five cases. Cancer Chemother Pharmacol 2011;68:1325-1330.

88 Araki T, Takashima A, Hamaguchi T, Honma Y, Iwasa S, Okita N, et al: Amrubicin in patients with platinum-refractory metastatic neuroendocrine carcinoma and mixed adenoneuroendocrine carcinoma of the gastrointestinal tract. Anticancer Drugs 2016;27:794799.

89 Bazerbachi F, Kermanshahi TR, Monteiro C: Early precursor of mixed endocrine-exocrine tumors of the gastrointestinal tract: histologic and molecular correlations. Ochsner J 2015; 15:97-101.

90 Frilling A, Modlin IM, Kidd M, Russell C, Breitenstein S, Salem R, et al: Recommendations for management of patients with neuroendocrine liver metastases. Lancet Oncol 2014;15:e8-e21.

91 Pavel M, O’Toole D, Costa F, Capdevila J, Gross D, Kianmanesh R, et al: ENETS Consensus Guidelines Update for the Management of Distant Metastatic Disease of Intestinal, Pancreatic, Bronchial Neuroendocrine Neoplasms (NEN) and NEN of Unknown Primary Site. Neuroendocrinology 2016;103: 172-185.

92 Arnold R, Wittenberg M, Rinke A, SchadeBrittinger C, Aminossadati B, Ronicke E, et al: Placebo controlled, double blind, prospective, randomized study on the effect of octreotide LAR in the control of tumor growth in patients with metastatic neuroendocrine midgut tumors (PROMID): results on long-term survival. J Clin Oncol 2013;31:4030. 
93 Caplin ME, Pavel M, Cwikła JB, Phan AT, Raderer M, Sedláčková E, et al: Lanreotide in metastatic enteropancreatic neuroendocrine tumors. N Engl J Med 2014;371:224-233.

94 Strosberg J, El-Haddad G, Wolin E, Hendifar A, Yao J, Chasen B, et al: Phase 3 trial of ${ }^{177} \mathrm{Lu}-$ Dotatate for midgut neuroendocrine tumors. N Engl J Med 2017;376:125-135.
95 Yao JC, Shah MH, Ito T, Bohas CL, Wolin EM, Van Cutsem E, et al: Everolimus for advanced pancreatic neuroendocrine tumors. N Engl J Med 2011;364:514-523.

96 Yao JC, Fazio N, Singh S, Buzzoni R, Carnaghi C, Wolin E, et al: Everolimus for the treatment of advanced, non-functional neuroendocrine tumours of the lung or gastrointestinal tract (RADIANT-4): a randomised, placebo-controlled, phase 3 study. Lancet 2016;387:968977.
97 Scarpa A, Chang DK, Nones K, Corbo V, Patch A-M, Bailey P, et al: Whole-genome landscape of pancreatic neuroendocrine tumours. Nature 2017;543:65-71.

98 Vilar E, Gruber SB: Microsatellite instability in colorectal cancer - the stable evidence. Nat Rev Clin Oncol 2010;7:153-162. 